\title{
Sustaining agriculture and development: Challenges for the future
}

\author{
Charles A. Francis
}

Agricultural scientists hold some of the pieces to the complex puzzle of how food production can be sustained into the future. This includes integration of knowledge from basic biological sciences with practical results from adaptive field research. The global challenge is to use this knowledge to confront the growing dilemma of how to intensify agriculture with a diminishing fossil fuel resource base, how to feed an exploding human population, and how to protect the environment.

To achieve this will require an adjustment in thinking about agricultural development beyond that of the perspective involved in the human domination of nature with industrial, chemical-dependent technology. A philosophy of food production and development is emerging that depends on intensive and efficient use of renewable resources, elevates information and management as substitutes for non-renewable energy-based resources, and seeks a balance with nature that allows a good quality of life for humans and the survival of most other species. I suggest ten ways to translate this philosophy into practical programs.

Encourage interdisciplinary research

Despite the growth of interdisciplinary research, task forces, teams, and integrated centers, the majority of professional time is still dedicated to narrow subject matter areas. Most agricultural scientists have been unwilling, unprepared, or lacking in confidence to deal with the complex, larger questions in development.

There are many reasons for this narrow focus. Professional orientation and training have concentrated on specific disciplines. Formal course work and dissertation research restrict the exposure to ideas, methods, or results from other departments. What we develop are discipline-specific words, meanings, and dialects, narrow groups of professional contacts, and

Paper No. 9027, Journal Series, Agricultural Research Division, University of Nebraska, Lincoln.

Charles A. Francis is Professor of Agronomy and Extension Crops Specialist, University of Nebraska, Lincoln, NE 68583-0910. a world view that considers one's own field, whether soil chemistry or genetic engineering or basic biotechnology or any other, to hold key answers to most of humankind's current and future problems. Professional reward systems - advancement and salary increases - are dependent on peer review within specific disciplines and administrative analysis of refereed publications. Young scientists are rarely encouraged to think broadly about global issues. Today's agricultural scientists are products of this professional environment.

Is it possible to move beyond this narrow focus on problems within disciplines? Can scientists learn to explore new ways to fit the puzzle pieces together? Are there methods and measurement tools that can contribute to more effective evaluation of the broader impacts of specific technologies? Interdisciplinary teams are needed to address these complex problems. The broadening of outlook gained by working with different specialists helps each participant to view cropping and farming systems in a more holistic way. This is a valuable stride toward interpreting research results in a long-term global perspective.

Explore innovative farming systems

Rather than carefully fine tuning present monoculture (single species) cropping systems, such as continuous corn production, scientists need to explore more complex systems that are productive and sustainable, often more so than conventional systems. Yet university specialists persist in comparing monoculture with multiple cropping, or continuous corn with rotation crops. This could be called "agronomic trivial pursuit." Resources can better be spent studying and exploiting rotation effects and biological diversity, seeking more sustainable systems based on renewable resources, and attempting to mimic stable natural systems. A diverse mix of crops and enterprises will lead to a better distribution of labor use through the year. Such systems also protect against drastic changes in climate; input costs, and prices of individual commodities.

Evolve from "product use" to "problem solving process" mentality

Heavy reliance on technology to solve problems in agriculture has promoted a "product mentality." When a farmer has weeds in the soybean field, the first question to extension specialists is probably, "What herbicide can I spray to kill the weeds?" 
A more logical, process-oriented approach would be for the farmer and extension specialist to study the kinds, sizes, and numbers of weeds in the field and stage of the crop, and then to evaluate a range of management options. Herbicide application is only one of many alternatives. To follow "process" further, it is important to determine what characteristics of the system have allowed weeds to become a problem and what modifications could reduce the density or germination of weed seeds. It often is possible to substitute information or management for a purchased input, thus reducing production costs and the potential for environmental contamination.

Combine linear planning with cyclical thinking

Farmers typically plan their cropping sequences, input use, and cultural practices in a straight-line manner through the crop year and into subsequent years. This means that when soluble fertilizers or pesticides are applied, the farmer assumes that they either are used by the crop or remain where they will not be harmful. Also, if some materials move into an aquifer or downstream, they have gone beyond the boundaries of traditional farmer concern. But in today's world, everyone lives downstream and within the same global boundaries and cycles of water and nutrients.

Monoculture systems represent a "linear species approach" to input use and cropping, whereas crop rotations and diverse systems promote greater cycling of nutrients. They also stimulate thinking about the natural cyclical processes in the system. Understanding nutrient cycles, hydrologic patterns, biological interactions, and natural species succession is part of the process. Intensive human involvement and management of each field provide an appreciation of the farming system and how its components fit together.

Involve professional women in agriculture

Women are hardly at all involved in the administration and technical sector of agriculture, even though in many cultures they make many production decisions, especially for horticultural crops. This means that in the critical game of food production, planning and research, half the team is off the court. Indeed, in some countries, women have not even been invited to the game. Yet the missing female players are perhaps the very ones who can see the problems more broadly and who can integrate the quest for production with needs for nutrition, health, and quality of life. Redressing their under-representation in research and extension is neither a woman's nor a man's problem; it is a human challenge.

\section{Understand the fragility of the natural environment}

Until there is broader appreciation of the sensitivity and fragility of the natural environment that sustains human life, it is unlikely that most people in agriculture will seriously challenge the sustainability of the current "domination mentality." Warning signals on the farm and in the community include loss of soil, chemical contamination of water systems, and disappearance of wildlife habitat. On the world scene, there is loss of the ozone layer, a worldwide warming trend, destruction of the tropical rain forest, and non-degradable wastes in the oceans. Can we expect all these problems to be solved with a new product or application of another fossil fuel-dependent technology? Is it likely that the effects of that technology are neutral to the environment? Developing new technologies and getting farmers to adopt them has been easier than evaluating their long-term impacts on the environment. We need not only to assess carefully both the benefits and the costs of each technology, but also to have the courage to leave some of these advances "on the shelf" for now. As a popular bumper sticker states, "Nature Bats Last"!

\section{Adapt to the reality of finite fossil fuels}

Most agricultural research continues to pursue solutions that depend on fossil fuels. This strategy has often been highly successful, increasing productivity per unit land area, per human, and per unit of labor invested in agriculture. As population continues to increase and resources become scarce, it is time to answer an even greater challenge: how to live within this constraint and design a food system that will be sustainable for the future.

The needed strategy will maximize efficient use of renewable resources - soil nutrients in organic and mineral fractions, rainfall, solar energy - while using fossil energy only when it is absolutely essential. This strategy preserves non-renewable energy sources for the indefinite future for uses where no alternative can be found. Other sectors outside of agriculture transportation, heating and cooling systems, food preparation, industry - must seek similar solutions.

\section{Accept responsibility for broader issues}

Most agricultural scientists view their role as contributing basic knowledge in specific disciplines. This view has created a generation of competent but narrowly focused technicians. Is it possible to break from this pattern and become involved in broader, long-range issues facing humankind?

The first step is to become aware that larger problems exist than can be addressed in each department. The second is to gain confidence that specialists can make useful contributions in wider arenas. Scientists often discuss problems larger than those in their own fields but then retreat into jobs where they feel more secure. It takes courage to move beyond the traditional role of agricultural scientist.

\section{Extend the time frame to consider longer term solutions}

Most human activity and thinking take place in the here and now. Research must be planned toward the time when results will be available to integrate into practical production systems. This takes at least 3 to 5 years with most agronomic research and 10 to 15 years in plant breeding. Therefore, it is crucial to anticipate what primary systems will look like a decade or two from now. How will new component technologies fit together? Is it possible today to anticipate the resource constraints and economic/environmental incentives that will prevail after the year 2000 and to develop technologies appropriate for them? Why not design the future? The projection of current trends is a shallow and fatalistic approach. Human ingenuity makes it possible to plan what kind of future we want and to decide what types of food and industrial systems would provide for basic needs and a broader quality of life and then take steps to make that future happen.

Broaden human focus to the global community

Agriculture is a competitive business. It must compete for (continued on page 192) 
(continued from page 99)

energy resources needed for fertilizer, chemicals, and fuels, for credit from commercial sources, and for capital and labor. Also, U.S. farmers compete for world markets and must adapt to changes in supply and demand for various commodities. Valueadded products provide an economically attractive alternative to exporting only low-value, high-volume feed grains. This change in global focus is essential to the continued health of agriculture in the U.S. as long as the primary crops are feed grains and many markets are beyond national borders.

Another dimension of a globalized agriculture that often does not concern the U.S. farmer or commodity exporter is the impact of basic food imports on farmers overseas. When commodities are imported just before harvest, local prices may be depressed below the break-even level. If this disincentive to local production causes farmers to shift to cash crops or other pursuits, a region or country can become highly dependent on economy and food supply is beyond the control of the individual farmer and country.

The cost of food imports adds to an already difficult international debt. Although comparative advantage and production efficiency on a world scale make sense in a perfect world, that world does not exist. In the real world there are droughts, unstable world energy prices, trade embargoes, large debts and interest payments, highest bidders, and political alliances. In today's global agriculture and international food industry, there is good reason for every country to achieve a degree of selfsufficiency in basic grains. It also is important for exporting countries and their producers to respect the needs of farmers and governments everywhere.

Conclusion: Meeting these future challenges limit population? Can institutions and individuals learn to face the real issues that will determine the earth's long-term ability to produce food and meet human needs? Will this be done in a resource-efficient way that preserves other options for future generations and within an ecological context that guarantees a reasonable quality of life for humankind everywhere?

The current sustainable agriculture debate has generated some of the right questions and reflects a broad concern about resource issues and ground water quality. Non-governmental, private research and development groups, and industry specialists are full participants in the debate about what a sustainable agriculture should be. This is an exciting time of change.

Geographic horizons have broadened so that farmers in $\mathrm{Ne}$ braska listen to weather reports from Brazil and Argentina and follow the markets in Europe and the U.S.S.R. There is concern about grain market grades, producing and exporting quality products, and varying production of specific grains and types for specialized markets. Debate on the U.S. farm bill considers global trade, competitiveness, and costs of production. Ground water issues take on regional dimensions, and more people express concerns about global climate.

Yet there is a long way to go. The economic plight of Midwest farmers is closely tied to that of producers in other major external sources of grain. The resulting harm to the national

Are we willing to pursue these challenges? Can we effectively

exporting countries. Exports to developing countries depend on their governments' decisions on how or whether to subsidize domestic grain production and the U.S. government's decisions on whether to provide food or economic assistance. It is important to respect the course set by other countries to meet their long-term food needs without putting economic or political pressure on them to adopt a strategy that is only favorable to U.S. exporters. For agriculture and the world economic order to be stable, the strategy needs to benefit all countries.

Hunger and food issues are not merely regional nor national, but global. Women's issues are really human issues. Political stability that comes with participatory systems and resource equity benefits everyone in the long run, and environmental concerns affect everyone. Extravagant energy investments in military hardware, personal transportation, short-lived creature comforts, and disproportionate benefits for a few favored nations do not promote long-term human species survival. Following a "business as usual" mentality and letting current economic structures and negotiations "sort things out" will not solve these challenges.

We must view ourselves as one species in a global ecosystem and as members of a global community, concerned about resources, environment, and the well-being of our descendants. Increasingly, global interests must take precedence over national and individual goals, and we need equitable methods to establish these priorities. Can we make these major and necessary adjustments in thinking? Can we afford a sustainable agriculture? Indeed, we cannot afford any other type of agriculture! This is the only game in town. There is no rational alternative to developing a sustainable agriculture. The human species must mobilize its most creative talent to meet the challenge.

Note: The author expresses appreciation for the thoughtful and comprehensive comments from Dr. William Lockeretz, Technical Editor.

\section{Federal budget has $\$ 4.45$ million for LISA Program}

The FY1990 Federal budget signed by the President in November, 1989 , has $\$ 4.45$ million for the 1990 round of LISA grants. That is the same amount as was allocated in the FY1989 budget. According to Program Director Neill Schaller, the budget only allowed support of 13 percent of the eligible proposals in 1989. While interest in LISA projects has continued to grow, its funding still stays at the level of onehalf of one percent of the total USDA research and education budget.
American Journal of Alternative Agriculture 